\title{
Optimal site selection for sitting a solar park using multi-criteria decision analysis and geographical information systems
}

\author{
Andreas Georgiou and Dimitrios Skarlatos \\ Civil Engineering \& Geomatics Dept., Cyprus University of Technology, 30 Archbishop Kyprianou Str., \\ 3036 Limassol, Cyprus \\ Correspondence to: Andreas Georgiou (angeocy@gmail.com)
}

Received: 23 February 2016 - Published in Geosci. Instrum. Method. Data Syst. Discuss.: 17 March 2016

Revised: 27 June 2016 - Accepted: 6 July 2016 - Published: 26 July 2016

\begin{abstract}
Among the renewable power sources, solar power is rapidly becoming popular because it is inexhaustible, clean, and dependable. It has also become more efficient since the power conversion efficiency of photovoltaic solar cells has increased. Following these trends, solar power will become more affordable in years to come and considerable investments are to be expected. Despite the size of solar plants, the sitting procedure is a crucial factor for their efficiency and financial viability. Many aspects influence such a decision: legal, environmental, technical, and financial to name a few. This paper describes a general integrated framework to evaluate land suitability for the optimal placement of photovoltaic solar power plants, which is based on a combination of a geographic information system (GIS), remote sensing techniques, and multi-criteria decision-making methods.

An application of the proposed framework for the Limassol district in Cyprus is further illustrated. The combination of a GIS and multi-criteria methods produces an excellent analysis tool that creates an extensive database of spatial and non-spatial data, which will be used to simplify problems as well as solve and promote the use of multiple criteria. A set of environmental, economic, social, and technical constrains, based on recent Cypriot legislation, European's Union policies, and expert advice, identifies the potential sites for solar park installation. The pairwise comparison method in the context of the analytic hierarchy process (AHP) is applied to estimate the criteria weights in order to establish their relative importance in site evaluation. In addition, four different methods to combine information layers and check their sensitivity were used. The first considered all the criteria as being equally important and assigned them equal weight, whereas
\end{abstract}

the others grouped the criteria and graded them according to their objective perceived importance. The overall suitability of the study region for sitting solar parks is appraised through the summation rule.

Strict application of the framework depicts $3.0 \%$ of the study region scoring a best-suitability index for solar resource exploitation, hence minimizing the risk in a potential investment. However, using different weighting schemes for criteria, suitable areas may reach up to $83 \%$ of the study region. The suggested methodological framework applied can be easily utilized by potential investors and renewable energy developers, through a front end web-based application with proper GUI for personalized weighting schemes.

\section{Introduction}

Energy is an essential part of modern life as almost all human activities are strongly connected with it. The availability and secure supply of energy are considered important prerequisites of economic and social development of a country. Although in the current economic situation, the rational use of the available resources and the need to overcome the negative environmental impacts and other problems associated with fossil fuels have forced many countries to enquired into and change to more environmentally friendly alternatives, which are renewable in order to sustain the increasing energy demand (Sanchez-Lozano et al., 2013; Bahadori and Nwaoha, 2013).

Among the renewable power sources, solar has grown exponentially worldwide during the last decade. This is not surprising as the sun can provide more than 2500 terawatts (TW) 
of technically accessible energy over large areas of Earth's surface and solar energy technologies are no longer cost prohibitive (Hernandez et al., 2014). However, currently it only covers a minor portion of global energy demands $(0.05 \%$ of the total primary energy supply) as photovoltaic (PV) power generates less than $1 \%$ of total electricity supply (Solangi et al., 2011); nevertheless, solar energy has great future potential.

Solar energy is obviously environmentally advantageous relative to any other non-renewable energy source and the linchpin of any sustainable development program. It can be exploited through the solar thermal and PV routes for various applications. The main direct or indirectly derived advantages of solar energy are no emission of greenhouse or toxic gasses, reclamation of degraded land, reduction of transmission lines from electricity grids, and increase of regional/national energy independence. In addition, it can provide diversification and security of the energy supply, acceleration of rural electrification in developing countries, job opportunities, improvement of life quality in developing countries, and investment security for park development as solar panels are resistant to extreme climate conditions with a life expectancy greater than 35 years (Solangi et al., 2011; Tsoutsos et al., 2005; Torres-Sibille et al., 2009; Hernandez et al., 2014). However, conflicts can also arise between renewable energy and nature conservation policy. The environmental impacts from photovoltaic power generation include general effects on visual impact, land use intensity, wildlife impacts, reflection effects, depletion of natural resources, and waste management (Torres-Sibille et al., 2009; Tsoutsos et al., 2005; Turney and Ftenakis, 2011). Although the number of direct animal deaths at solar parks, is thought to be negligible (Katzner et al., 2013). The worst impacts of groundmounted solar installations occur when all natural habitat in the vicinity is cleared, stripping vegetation and compacting soil. This can reduce the carbon content of the soil compared to undisturbed areas and, in arid regions, allows for the transport of dust, which can reduce the efficiency of solar panels (Hernandez et al., 2014). Other risks to wildlife from solar park operation include chemicals such as dust suppressants and rust inhibitors (Hernandez et al., 2014). Water is also used to clean the panels, which may pressurize scarce resources in dry regions (Cameron et al., 2012). It is also important to take into account the life-cycle assessment: processes involved in obtaining rare materials used for making solar panels may lead to biodiversity impacts elsewhere, e.g., at the source of extraction (European Commission, 2014).

The sitting of photovoltaic power facilities is important in order to maximize the potential of the PV technology implementation in reality. Any site selection and assessment procedure must address the technical, economic, social, and environmental aspects of the project to determine whether it is suitable for solar energy development. As a result, energy and electricity industry professionals and policy groups have developed a variety approaches to mitigate sitting of so- lar parks. A geographic information system (GIS) is a popular and effective decision-making tool for the selection of optimal sites for different types of activities and installations (Carrion et al., 2008; Tegou et al., 2010; Kontos et al., 2005). Applications of GISs and renewable energy source planning include wind farm sitting, photovoltaic electrification, biomass evaluation, visual impact assessment of wind farm, etc. (Tegou et al., 2010; Georgiou et al., 2012; Masera et al., 2006; Ramachandra and Shruthi, 2007). One of the most common GIS-based strategies that have been designed to facilitate decision making in site evaluation and land suitability is multi-criteria analysis (MCA) (Torres-Sibille et al., 2009). The analytic hierarchy process (AHP) method that introduced by Saaty (1980) is a flexible and easily implemented MCA technique and its use has been largely explored in the literature with many examples in locating facilities and land suitability analysis (Tegou et al., 2010; Kontos et al., 2005; Georgiou et al., 2012; Masera et al., 2006).

The scope of this paper is to develop and present an integrated framework to quantify and evaluate land suitability for the optimal photovoltaic solar power plant placement with an application to the Limassol district in Cyprus. This should be considered as a tool, which different users can change its respective weights in order to produce a custom made map for their own "most suitable" areas for solar park investment. The proposed framework comprises of a combination of already established methods and tools for solar resource assessment, remote sensing techniques, spatial analysis, and multi-criteria decision-making methods. The AHP has been chosen as a means of weighting the suitability criteria, the simple additive weighting (SAW) method has been used as an aggregation algorithm, and a GIS as an integrated platform of analysis and presentation. Innovative aspects comprise of a unique and balanced approach among practice, law, and theory of solar park siting. In order to do so, a real application area was selected for implementation. A novel methodology was adopted, which takes into consideration several constraints and many criteria that have been pre-quantified. In addition, a straightforward integration was developed using seamless existing tools for analysis, modeling and representation in a single GIS environment, allowing for a flexible tool that encourages several "what if" scenarios to be easily implemented. The tool, currently implemented within a local GIS, has a prospect for future web automation.

\section{Material and methods}

The methodological framework considers that each potential site that may host a solar park should satisfy a number of functional parameters and assesses their comparative importance. To do so, a combination of MCA with a GIS were used, with the AHP method as additional tool to assign weight of relative importance to each evaluation criterion. An 


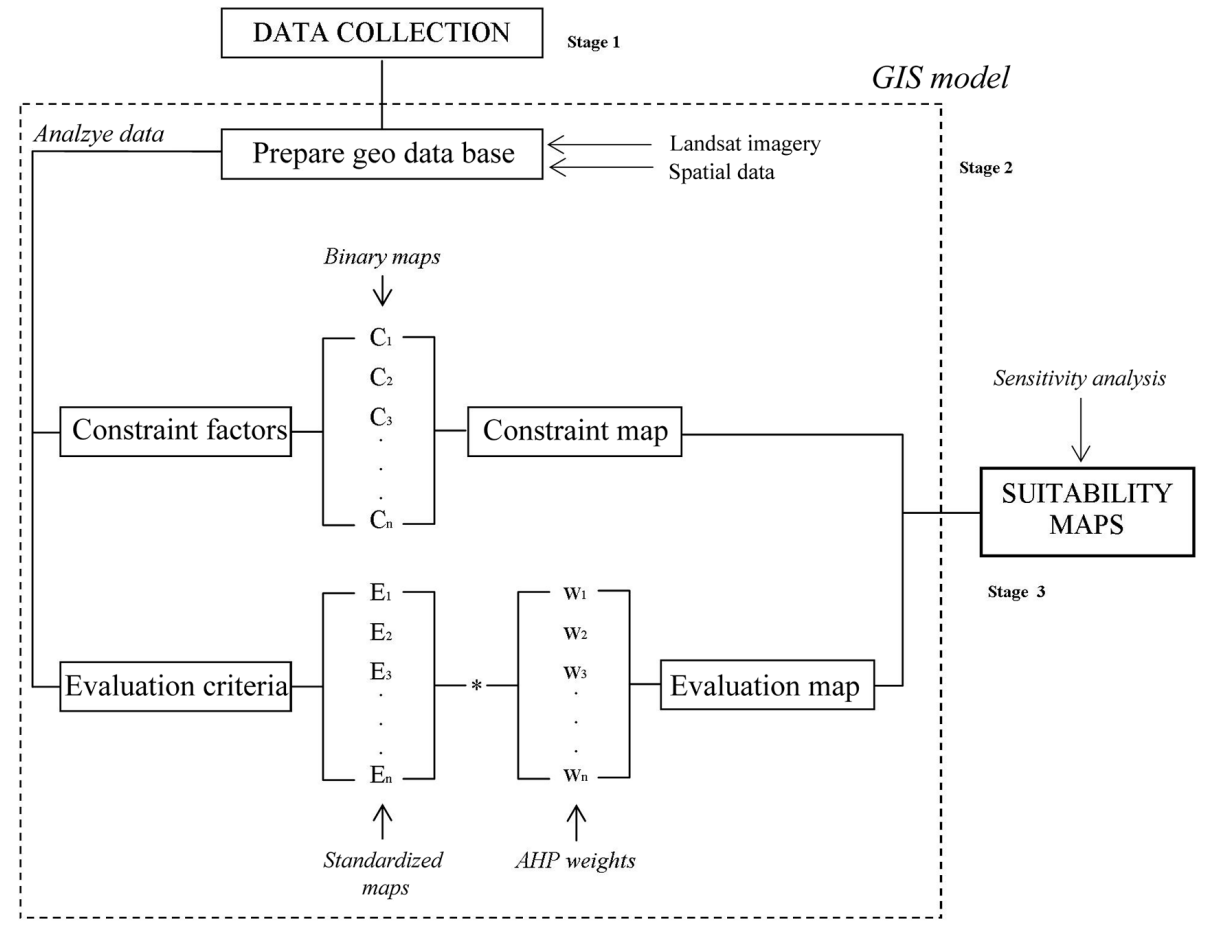

Figure 1. Flow chart of proposed methodology framework.

overall suitability index (SI) is then calculated for each potential cell in the map using the weighted overlay technique.

The presented methodological framework involves several stages as presented in Fig. 1 and were grouped as (i) collection of data, (ii) setup of the GIS model, (iii) sensitivity analysis, and (iv) extraction of the suitability maps. More specific, the first step is to define and gather all appropriate data layers needed for the analysis in order to set up the digital geo-database. The next step is to establish the constraint factors that will determine unsuitable areas and will be in the form of a binary map, where " 0 " refers to unsuitable areas and " 1 " to areas suitable for further examination for solar exploitation. At the exclusion areas, local and EU legislation was used to define criteria in addition to GIS and remote sensing techniques. The next step is to establish the cost functions for all available criteria and estimation of weights of the evaluation criteria according the AHP algorithm. These weights are based on subjective criteria that can be changed according to the needs of researchers. The final step consists of the formulation and calculation of the final suitability index map using the SAW method and the presentation of the results in thematic maps.

The definition of both bounding constraints and evaluation criteria depended on standing legislation and on the characteristics of the study area. All factors were selected in accordance with the Cypriot legislation for renewable energy sources (RES) sitting (Law 29(I), 2005) and in some cases, under the advice of the experts of the Ministry of Agriculture Natural Resources \& Environment. In addition, European's
Union policy (European Commission, 2014) and previous similar research in the renewable energy systems field (European Commission, 2014; Carrion et al., 2008; Katsaprakakis, 2012; Mari et al., 2011) are used to configure the list of parameters that are used.

\subsection{The AHP Method}

The AHP is a multi-criteria decision-making approach that can be used for solving complex and unstructured problems. It helps to capture both qualitative and quantitative aspects of a decision problem and provides a powerful yet simple way of weighting the decision criteria, thus reducing bias in decision-making (Saaty, 1987; Georgiou et al., 2012). The AHP is based on pairwise comparisons and used to derive normalized absolute scales of numbers, whose elements are then used as priorities. By comparing pairs of criteria one at a time and using integer numbers from the 1 to 9 scale of the AHP, decision-makers can quantify their judgment about the relative importance of criteria. Then a pairwise comparison matrix is formed where the relative importance weight of each criterion is computed as the normalized geometric mean of each row of the matrix. A consistency index (CI) that measures the inconsistencies of pairwise comparison calculated as follows (Eq. 1), where $\lambda \max$ is the largest eigenvalue and $n$ the number of rows or columns:

$\mathrm{CI}=\frac{\lambda \max -n}{n-1}$. 
A measure of coherence of the pairwise comparisons is calculates in the form of consistency ratio (CR) where RI is the average $\mathrm{CI}$ of the randomly generated comparisons (Pilavachi et al., 2009):

$\mathrm{CR}=\frac{\mathrm{CI}}{\mathrm{RI}}$.

CR value of $10 \%$ or less is considered as acceptable; otherwise, one has to revise his judgments.

\subsection{Simple additive weighting method}

The SAW method is the simplest way for aggregating the used criteria in order to compute a SI for each cell in the study area. More specific, each evaluation criterion is multiplied by the respective weight and then all criteria are summed in order to provide a total performance score for each cell. The SI lies between 0 and 100, corresponding to the "worst" and "best" sites, respectively. The applied formulation is (Georgiou et al., 2012)

$\mathrm{SI} i=\sum_{j=1}^{n} W j \cdot V i j$,

where SI $i$ is the overall suitability index for cell $i, W j$ the relative importance weight of criterion $j, V i j$ the score of cell $i$ under criterion $j$, and $n$ the total number of criteria.

\section{Case study}

\subsection{Study site}

Located in the southern part of the island of Cyprus (Fig. 2), the study area of Limassol district covers an area of about $1370 \mathrm{~km}^{2}$. The island of Cyprus is located in the northeastern part of the Mediterranean Sea and therefore, has a typical eastern Mediterranean climate with a long hot dry summer, mild winter, and more than $3000 \mathrm{~h}$ of sunshine annually. One of the most important aspects of the Cypriot budget is energy, as it is characterized by high dependence on imported energy sources, the intense use of oil in the energy balance, isolation from European energy networks, and a low degree of exploitation of renewable energy sources. Regarding primary energy, $90 \%$ is oil based, $6 \%$ is coal based and the remaining $4 \%$ is based in solar energy and basically in solar thermal energy (Pilavachi et al., 2009; Maxoulis and Kalogirou, 2008). For those reasons, as well as the fact that Cyprus is an island, it must be as energy independent as possible.

\subsection{Preparation of the geo-database}

This study aims to develop a framework model using a GIS system, supporting satellite imagery and both rasters and vectors as input data. Spatial data sets of archaeological sites, road network, electricity grid, solar radiation, digital elevation model (DEM), NATURA 2000 areas, rivers, land use,

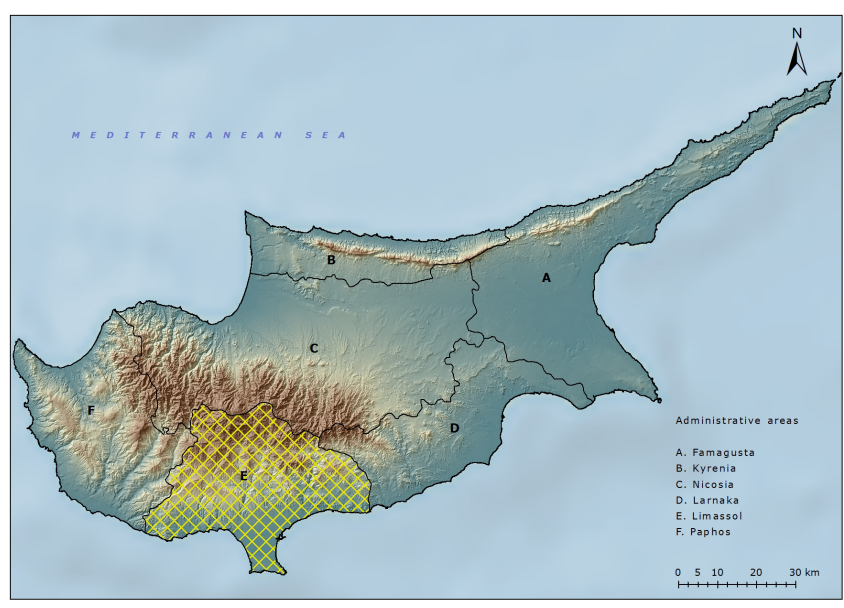

Figure 2. Study area of Limassol district.

built-up areas, surface waters, airport area, slope, and aspect are all part of the geo-database. This geo-database can be easily expanded with more layers of information, once they are available.

The land use, built-up areas, and surface waters were produced from the analysis of a Landsat- 8 OLI/TIRS image as further illustrated. The Landsat-8 OLI/TIRS image has been chosen, as the spatial resolution provided is suitable for the analysis and it is the same as DEM. The image was acquired on 26 September 2015 and contains 11 bands. Vector data such as archaeological sites, road network, rivers, and an airport were digitized by 1:50000 maps of Cyprus while NATURA 2000 areas and electricity grid were produced by the Ministry of Agriculture Natural Resources \& Environment and Electricity Authority of Cyprus (EAC), respectively. Finally, the DEM with spatial resolution of $30 \mathrm{~m}$ was produced by the Cyprus Geological Survey Institute using three parameters. The main parameter for DEM construction was the contours derived from 1:50000 maps of Cyprus, to this was then added several topographical points derived from aerial photography and photogrammetry, and, finally, rivers were used for parameter identification and geographic correction.

\subsection{Landsat-8 OLI/TIRS data pre-processing}

Landsat-8 satellite images are available through the U.S. Geological Survey (Zanter, 2016) Earth Resources Observation and Science (EROS) center. Landsat-8 carries two instruments: the Operational Land Imager (OLI) sensor includes refined heritage bands, along with three new bands: a deep blue band for coastal/aerosol studies, a shortwave infrared band for cirrus detection, and a Quality Assessment band (30 $\mathrm{m}$ resolution). The Thermal Infrared Sensor (TIRS) provides two thermal bands ( $100 \mathrm{~m}$ resolution). These sensors both provide improved signal-to-noise radiometric (SNR) performance quantized over a 12-bit dynamic range (Zan- 
ter, 2016). The satellite collects images of the Earth with a 16-day repeat cycle with the approximate scene size to be at $170 \mathrm{~km}$ north-south by $183 \mathrm{~km}$ east-west (Zanter, 2016).

Prior to deriving the spectral indices necessary for the analysis, the Landsat-8 OLI/TIRS data had to undergo radiometric calibration and atmospheric correction. The digital number $(\mathrm{DN})$ values of the multispectral and thermal bands had to be converted into top-of-atmosphere (TOA) reflectance and be corrected with sun angle.

The TOA spectral radiances of the multispectral and thermal bands of the Landsat- 8 OLI/TIRS imagery can be calculated using Eq. (4).

$L_{\lambda^{\prime}}($ Landsat -8$)=M_{L} Q_{\text {cal }}+A_{L}$,

where $M_{L}$ and $A_{L}$ are, respectively, the band-specific multiplicative and additive rescaling factors from the metadata; and $Q_{\text {cal }}$ is the quantized and calibrated standard product pixel values (DN) (Zanter, 2016).

In the correction of the reflectance with the sun angle, we used the TOA planetary reflectance without the sun correction $\left(L_{\lambda^{\prime}}\right)$ and the local sun elevation angle $(\theta \mathrm{SE})$ using Eq. (5). The scene center sun elevation angle in degrees is provided in the metadata. Source: (Zanter, 2016).

$L_{\lambda}=\frac{L_{\lambda^{\prime}}}{\cos \theta \mathrm{SE}}$

\subsection{Classification of main area categories}

In order to exclude certain areas from selection, the area of study (AoS) was grouped into three generalized categories, i.e., vegetation, open water, and built-up land. Based on these three elements, three indices, NDVI, MNDWI, and NDBI, were selected in this study to be used for extraction of those three major land-use classes, respectively.

\subsubsection{NDVI - derived vegetation image}

There are various vegetation indices to enhance vegetation information in remote sensing imagery usually by ratioing a near-infrared (NIR) band to a red band. This takes advantage of the high vegetation reflectance in NIR spectral range and high pigment absorption of the red light (Hangiu, 2007). Normalized Difference Vegetation Index (NDVI) is the best indicating factor for plant growth status and the spatial distribution of vegetation, which has a linear relationship with the density of vegetation distribution (Haoxu et al., 2011); the formula is shown as Eq. (6):

$\mathrm{NDVI}=\frac{\mathrm{NIR}-\mathrm{RED}}{\mathrm{NIR}+\mathrm{RED}}$

where NIR presents near-infrared wavelength and RED represents red wavelength. They belong to bands of the Landsat8 OLI/TIRS and respectively represented the fifth and fourth band.
Once the NDVI was finalized, a threshold of 0.45 was selected as most appropriate for the extraction of high vegetation locations.

\subsubsection{MNDWI - derived water image}

As the study area is crossed by several rivers and distributed with some reservoirs and small lakes, in order to extract surface water, the modified normalized difference water index (MNDWI) was adopted (Haoxu et al., 2011). The formula is as follow:

MNDWI $=\frac{\text { Green }- \text { MIR }}{\text { Green }+ \text { MIR }}$

where Green represents the green wavelength, MIR represents the middle-infrared wavelength, and they belong to bands of the Landsat- 8 OLI/TIRS and respectively represented the third and sixth band.

Based on the ground survey data and hence the information about the known eater body location, a threshold of 0.2 was selected as most appropriate for the extraction of surface water.

\subsubsection{NDBI - derived built-up image}

The built-up land image was produced using the normalized difference building index (NDBI), which takes advantage of the unique spectral response of the built-up lands that have a higher reflectance in MIR wavelength range than in NIR wavelength range (Zha et al., 2003); the formula is shown as Eq. (5):

$\mathrm{NDBI}=\frac{\mathrm{MIR}-\mathrm{NIR}}{\mathrm{MIR}+\mathrm{NIR}}$,

where MIR represents the middle-infrared wavelength, NIR the near-infrared wavelength, and they belong to bands of the Landsat-8 OLI/TIRS and respectively represented the fifth and sixth band. However, the resulted index map found that many vegetated areas have positive NDBI values and in some circumstances, water bodies can also reflect MIR stronger than NIR. Consequently, the contrast of the NDBI images is not as good as NDVI and MNDWI images, because many pixels of vegetation and water areas having positive NDBI values show medium gray tones and are presented as noise mixed with built-up features. Some studies address similar problems (Hangiu, 2007; Zha et al., 2003) with low accuracy in the final extraction of NDBI. These suggest that the urban built-up land features could not be extracted merely based on a NDBI image. In this study, a combination of NDBI with NDVI and MNDWI is used to extract urban built-up land features. This combination can remove the vegetation and water noise, and hence improve the extraction accuracy.

The method that used to extract built-up land features based in an "if-the-else" logic calculation through a band spectral signature analysis (Hangiu, 2007). A new image data 
Table 1. Constraint factors of the case study.

\begin{tabular}{lll}
\hline & Constraint factors & Type \\
\hline & The solar park must not be within: & \\
$\mathrm{C}_{1}$ & $50 \mathrm{~m}$ from primary and secondary roads & Social impact \\
$\mathrm{C}_{2}$ & High vegetation & Environmental/technical \\
$\mathrm{C}_{3}$ & $200 \mathrm{~m}$ from NATURA 2000 areas & Environmental \\
$\mathrm{C}_{4}$ & $200 \mathrm{~m}$ from national forest & Environmental \\
$\mathrm{C}_{5}$ & $200 \mathrm{~m}$ from urban zones & Social \\
$\mathrm{C}_{6}$ & $100 \mathrm{~m}$ from surface waters & Environmental \\
$\mathrm{C}_{7}$ & $2000 \mathrm{~m}$ from airport & Safety \\
$\mathrm{C}_{8}$ & $200 \mathrm{~m}$ from archaeological sites & Social impact \\
$\mathrm{C}_{9}$ & $200 \mathrm{~m}$ from shoreline & Social impact \\
$\mathrm{C}_{10}$ & Areas with aspect: east I west I north I northeast I northwest & Technical \\
\hline
\end{tabular}

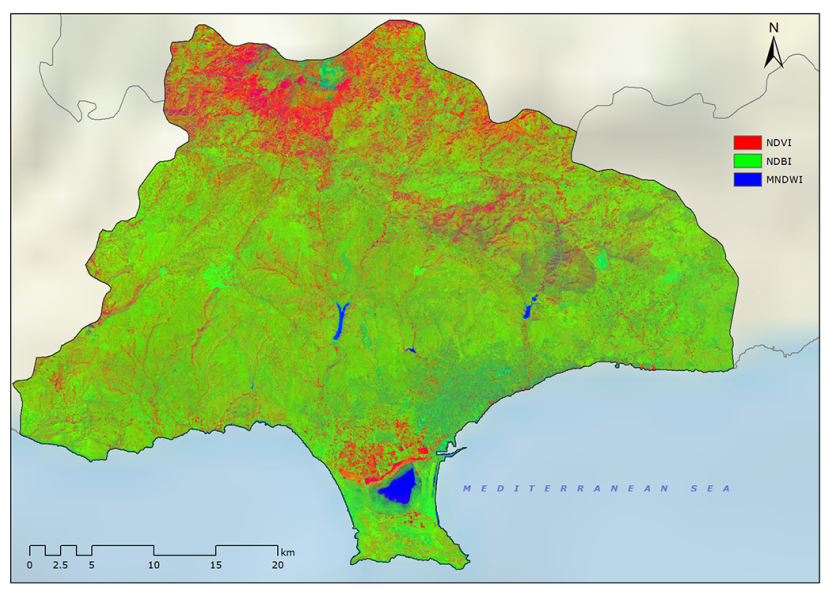

Figure 3. Results from Landsat 8 OLI/TIRS image classification in NDVI, NDBI, and MNDWI.

set was created, which used NDVI (Band1 - RED), NDBI (Band2 - GREEN) and MNDWI (Band3 - BLUE) images as three bands and the new classification image is presented in Fig. 3. A simple rule-based logic tree is used to segment urban built-up lands from non-urban built-up features. Examining the signatures of the three new bands found that there are no major differences between means of NDVI and NDBI that might cause confusion between built-up land and vegetation classes. Therefore, the logic calculation that is used to assist in the extraction is as follows:

\section{If BAND $1<0.15$ and BAND $2>$ BAND 3 then 1 Else 0}

The maximum of built-up land class in Band 1 (NDVI) is 0.15 , whereas the minimum of vegetation class in that band is 0.45 . Therefore, using 0.15 as a threshold value can help avoid the confusion between vegetation and built-up land classes and greatly increase the extraction accuracy.

To compare the extraction accuracy, the extracted data of built-up areas, high vegetation, and surface waters is checked by a reference map. A GeoEye Ikonos with finer spatial res- olution provided as base map in $\operatorname{ArcGIS}^{\mathrm{TM}}$ was used as a reference data set from which the extraction results were compared. A random sampling method was used to visually check the classification results against the higher-resolution satellite image.

\subsection{Establishment of constraints factors}

The constraint factors that were used are presented in Table 1 and comprise of environmental, safety, social (in terms of pressure in society), and technical parameters. A binary GIS mask is created for each constraint, with cells falling within a constrained area assigned " 0 " and the rest of them assigned "1".

The constraints $\mathrm{C}_{3}, \mathrm{C}_{4}, \mathrm{C}_{5}, \mathrm{C}_{8}$, and $\mathrm{C}_{9}$ are according the national legislation, while the $\mathrm{C}_{10}$ is set by experts to exploit the best performance of a solar panel that derives from areas with aspects south, southeast, and southwest. The $\mathrm{C}_{1}$ and $\mathrm{C}_{7}$ are set in way to avoid any reflections from the solar park in these directions and, finally, $\mathrm{C}_{2}$ and $\mathrm{C}_{6}$ are set by researchers under environmental and technical concern, respectively.

The constraint factors exclude $17 \%\left(227 \mathrm{~km}^{2}\right)$ of the district area.

\subsection{Establishment of evaluation criteria and normalization}

The evaluation criteria that score the potential sites are based mainly on financial parameters as presented in Table 2. After the evaluation criteria were determined and assessed, they were normalized through cost functions in a scale from 0 to 100 in order to allow for direct comparability, with 100 representing the most desired value (low cost) and 0 representing the most undesired value (high cost). Some standardize evaluation layers were calculated using an inverse distance cost function, i.e., main roads and distance from them. Figure 4 presents each standardized evaluation layer. This research focuses on developing a workbench GIS model for sitting solar parks and as such does not focus in detail on the cost functions themselves. It should be noted that once the 


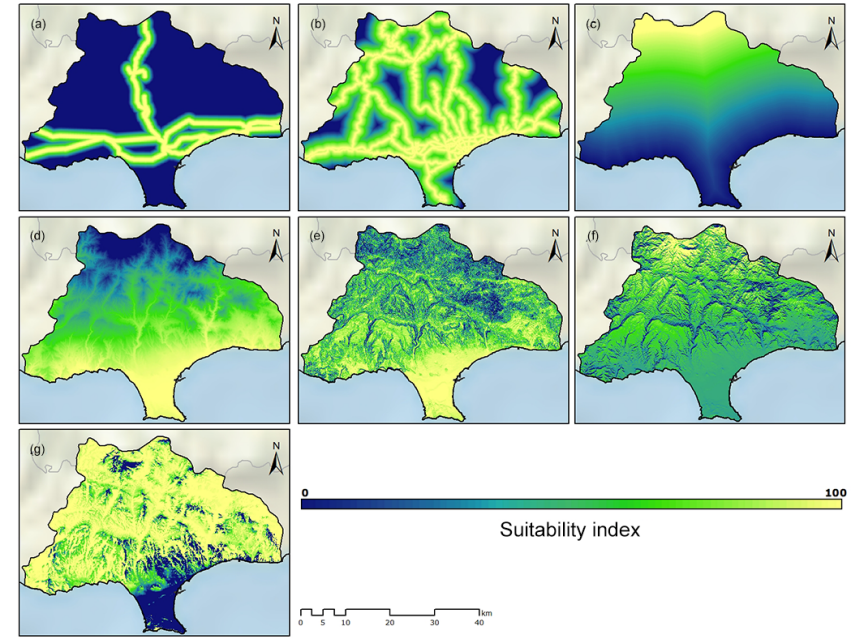

Figure 4. Standardized evaluation layers (a) electricity grid, (b) road network, (c) land value, (d) elevation, (e) slope, (f) solar energy, and (g) viewshed from primary roads.

Table 2. Evaluation criteria of the case study.

\begin{tabular}{lll}
\hline & Evaluation criteria & Type \\
\hline$E_{1}$ & Elevation & Technical \\
$E_{2}$ & Slope $<45^{\circ}$ & Technical \\
$E_{3}$ & Viewshed from primary roads & Social \\
$E_{4}$ & Land value & Financial \\
$E_{5}$ & Distance from road network $<2500 \mathrm{~m}$ & Financial/technical \\
$E_{6}$ & Distance from electricity grid $<2000 \mathrm{~m}$ & Financial/technical \\
$E_{7}$ & Solar radiation $>$ mean radiation of the area & Technical \\
\hline
\end{tabular}

GIS model has been established the cost functions and the weighting schemes can be easily adapted to support a more precise and detailed cost-function scheme. It should be noted here, that if the suggested method is to be used for financial investment analysis, then each of these cost functions can be further adjusted and updated to reflect local and contemporary financial practice. Further analysis of the cost functions will not be further analyzed here, as this is not the scope of the paper.

In technical terms, very steep slopes of land are not suitable for solar park installation. For that reason, land slopes greater than $45^{\circ}$ were excluded while the remaining got grading values of 0 to 100 . In addition, high altitude areas have higher transportation cost and are not preferable. Finally, solar radiation values greater than the mean value of the study area were taken into consideration, getting grading values from 0 to 100 .

On the other hand, in financial terms, the distance from road network and electricity grid increase the investment cost since additional infrastructure is necessary. In that way, areas farther than $2500 \mathrm{~m}$ from the road network and $2000 \mathrm{~m}$ from the electricity grid are considered as not economically viable and are assigned the value of " 0 ". Finally, the land value is strongly correlated with the distance from the shoreline, as seaside areas cost more and are therefore not affordable for such installations. Finally, in social terms, the visibility of potential sites from primary roads was taken into consideration with grading from 0 to 100 , where " 0 " presents high observation frequency and "100" zero visibility.

\subsection{Rationale for weights in AHP}

The AHP method is used to assign weight to the criteria as not all of them are equally important. The pairwise weight matrix for the calculation of the overall weights of the evaluation criteria is created (Table 3 ), and the priority weights estimated (Table 3). The AHP parameters are also shown, indicating that the original judgments are consistent.

The rationale behind the particular criteria weighting, is highlighted in the following.

- The solar radiation is considered to be the most important criterion since it determines the output of the solar park.

- The distance from electricity grid (EAC) and from roads follow, as they determine the final cost of installation.

- The slope and elevation pose are technical criteria that might increase the investment.

- The land value is thought to be less significant as it has only to do with the cost of the land that will host the solar park

- Finally, the viewshed from primary roads is placed last, as the social concern is considered less significant compared to the other criteria.

\section{Results}

\subsection{Suitable areas suggestions}

The suitability index map (Fig. 5c) is derived from the multiplication of the binary constraint map (Fig. 5a) with the evaluation map (Fig. 5b), hence totally removing the restricted areas from the evaluation map. The most appropriate areas for solar park installation are those shown in light yellow, with a suitability index of 70-80. Nevertheless, there are no best-ranked sites (with score 100) in the study area, showing that there are no sites with best grades in all criteria. It is also noticeable that most of the study area $(83 \%)$ is restricted from solar park installation, while only a considerably small percentage (1\%) of the area achieved a suitability index of 80 , even though solar energy is favorable in more areas. Finally, the distribution of the suitability index pixels presented in Fig. 5d, shows that most of the pixels have values around 60 and few of them with SI $>75$. 
Table 3. Case 2: pair-comparison matrix and relative importance weights in the last column.

\begin{tabular}{lcccccccc}
\hline & Viewshed & Land value & EAC & Slope & Solar & Elevation & Roads & Weight \\
\hline Viewshed & 1.000 & 1.000 & 0.333 & 0.500 & 0.111 & 0.500 & 1.000 & 0.037 \\
Land Value & 1.000 & 1.000 & 0.500 & 2.000 & 0.143 & 2.000 & 0.500 & 0.078 \\
EAC & 3.000 & 2.000 & 1.000 & 3.000 & 0.143 & 3.000 & 2.000 & 0.133 \\
Slope & 2.000 & 0.500 & 0.333 & 1.000 & 0.111 & 1.000 & 0.333 & 0.051 \\
Solar & 9.000 & 7.000 & 7.000 & 9.000 & 1.000 & 9.000 & 9.000 & 0.545 \\
Elevation & 2.000 & 0.500 & 0.333 & 1.000 & 0.111 & 1.000 & 0.500 & 0.052 \\
Roads & 1.000 & 2.000 & 0.500 & 3.000 & 0.111 & 2.000 & 1.000 & 0.105 \\
\hline
\end{tabular}

$\mathrm{CR}=0.071<0.1$

Constraint map

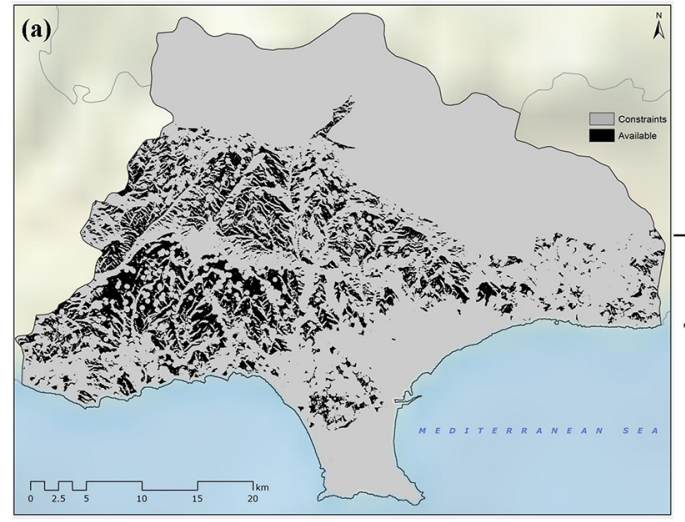

Evaluation map

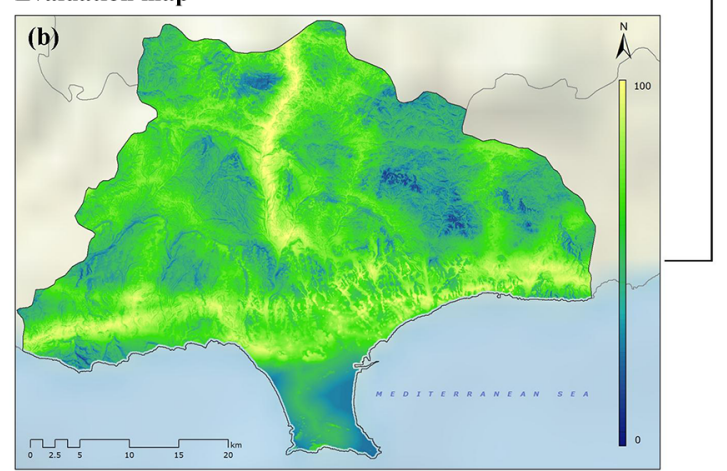

Suitability map

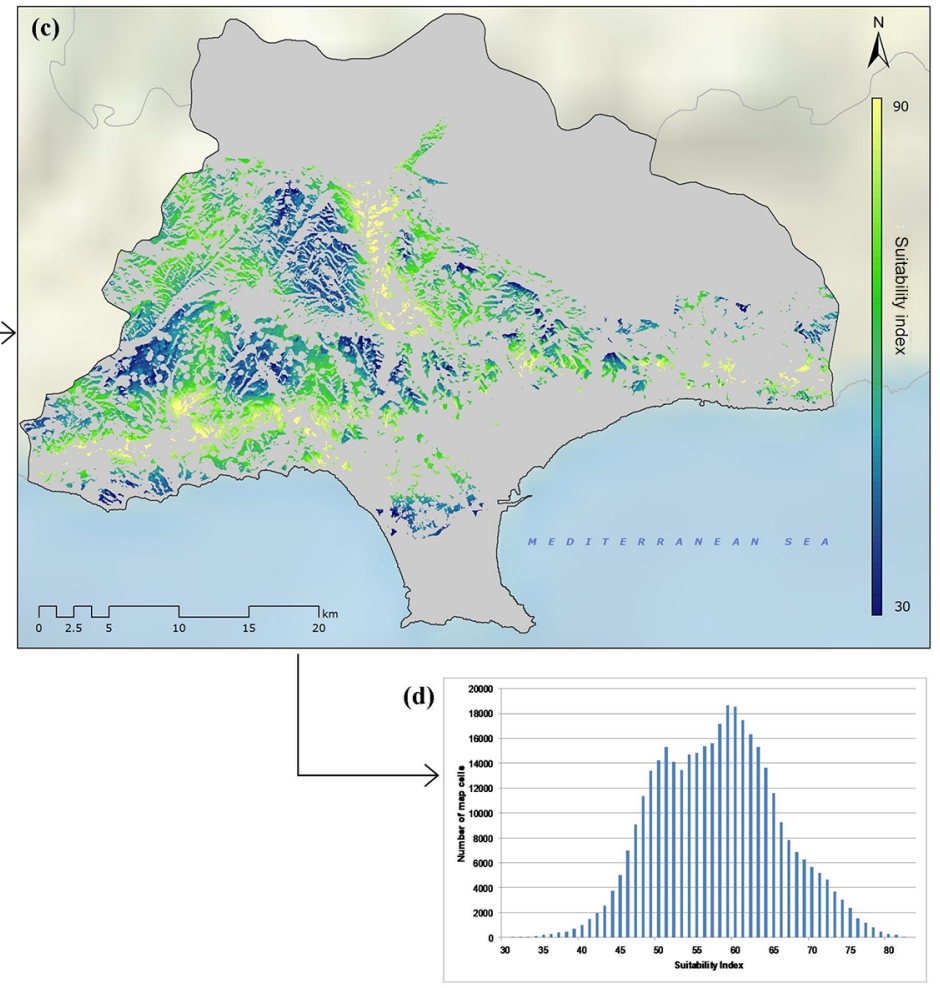

Figure 5. (a) Constraint map,(b) evaluation map, (c) the final suitability index map of study area as derived from the merging of constraint map and evaluation map, and (d) distribution of suitability index pixels over the final map.

\subsection{Sensitivity analysis}

In a multi-criteria analysis a "what if", sensitivity analysis is recommended as a means of checking the stability of the results against the subjectivity of the expert judgments. The most common method is to modify the weighting obtain from the experts, while the assumption of equal weighting is also used (Cameron et al., 2012). In this project, the sensitivity analysis performed considers the effect of changes of criteria weights upon the overall suitability index. To that aim, the following four cases were examined.
- Case 1: all criteria have the same weights.

- Case 2: the weight of the criterion "solar energy" has the biggest score and the rest are equally distributed.

- Case 3: the weight of the criteria "solar energy" and "land value" have the biggest score while the rest are distributed equally.

- Case 4: all economical criteria (road network, electricity grid, and land value) have weights equal to zero (0).

The results and statistics information of the four cases are illustrated in Fig. 6. As observed, the present framework is 

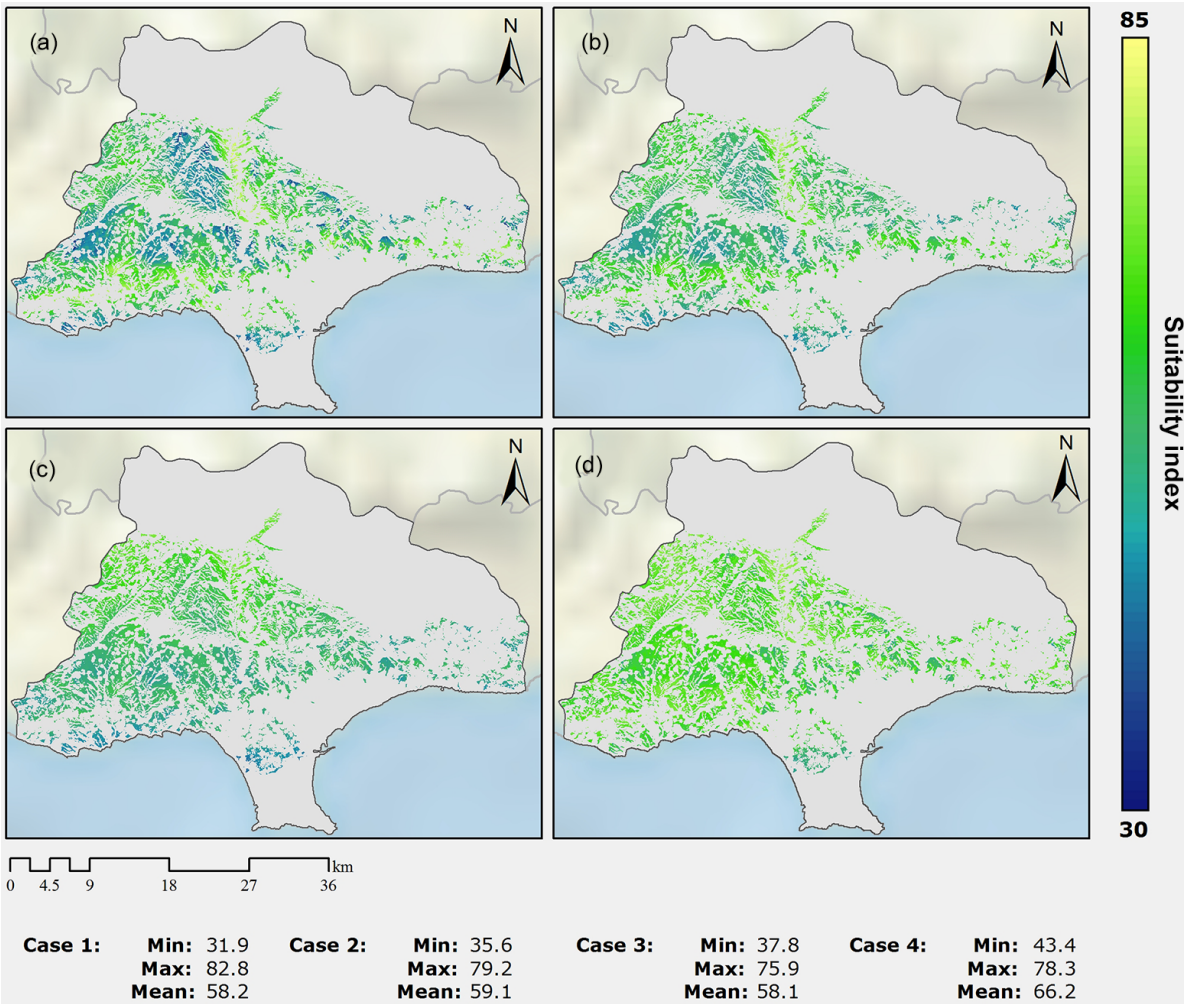

Figure 6. Sensitivity analysis results and comparison among different scenarios, which are not differentiating results: (a) case 1, (b) case 2 , (c) case 3 , and (d) case 4 .

sensitive to the criteria weights. This was expected since the evaluation criteria are selected with respect to the specific characteristics of the study area. The change of the final suitability map that is derived from the changing of criteria weights implies that each selected criterion is influential in the evaluation of the study area.

Figure 7 presents the results of the sensitivity analysis as classified into five classes in order to understand the variation of suitability index. It is obvious that depending the parameters that the user changes for each scenario, the respective suitability pattern varies over the study area.

It is noticeable that, although the resulting maps for the four cases of the sensitivity analysis show considerable modification in the suitability index, Fig. 8 shows that the number of the most suitable areas (SI $>75)$ for solar park sitting remains low and in some cases null. In case 4, where no economic criteria are taken into consideration, a noteworthy variation is observed; i.e., the majority of potential sites are classed from 45 to 60 with a few high scoring potential sites. In addition, a noticeable lack of potential sites with SI $>75$ observed in case 2 and case 3 with most of the pixels to be concentrated in SI $\sim 54$ and SI $\sim 50$, respectively. Finally, only in case 1 are pixels with high values presented, with SI values evenly distributed.

\section{Discussion}

The proposed method has been implemented in Limassol district. The SAW method was used to quantify several features that rule the decision of citing a solar park and create suitability index maps for every feature. The AHP method was used to establish weighting among the different features and merge the suitability index maps into a single evaluation map. Remote sensing classification was used to detect urban areas and water bodies and create a mask of exclusion areas. Additional masks of exclusion areas were created based on legal restrictions. The evaluation map and the exclusion masks were merged to create the final combined index map. Although the design of the proposed method seems complicated, it is straight forward and takes into consideration all possible aspects of a solar park siting. Any aspects that are overlooked can be easily added, and the potential user, may easily vary the weights according to his own priorities and local specifics.

In order to check the method's versatility, sensitivity, and adaptability, different scenarios were utilized to access the different results. As demonstrated (Figs. 6 and 7), the method produces different results upon different inputs; hence, one may adapt it to one's personal requirements. 

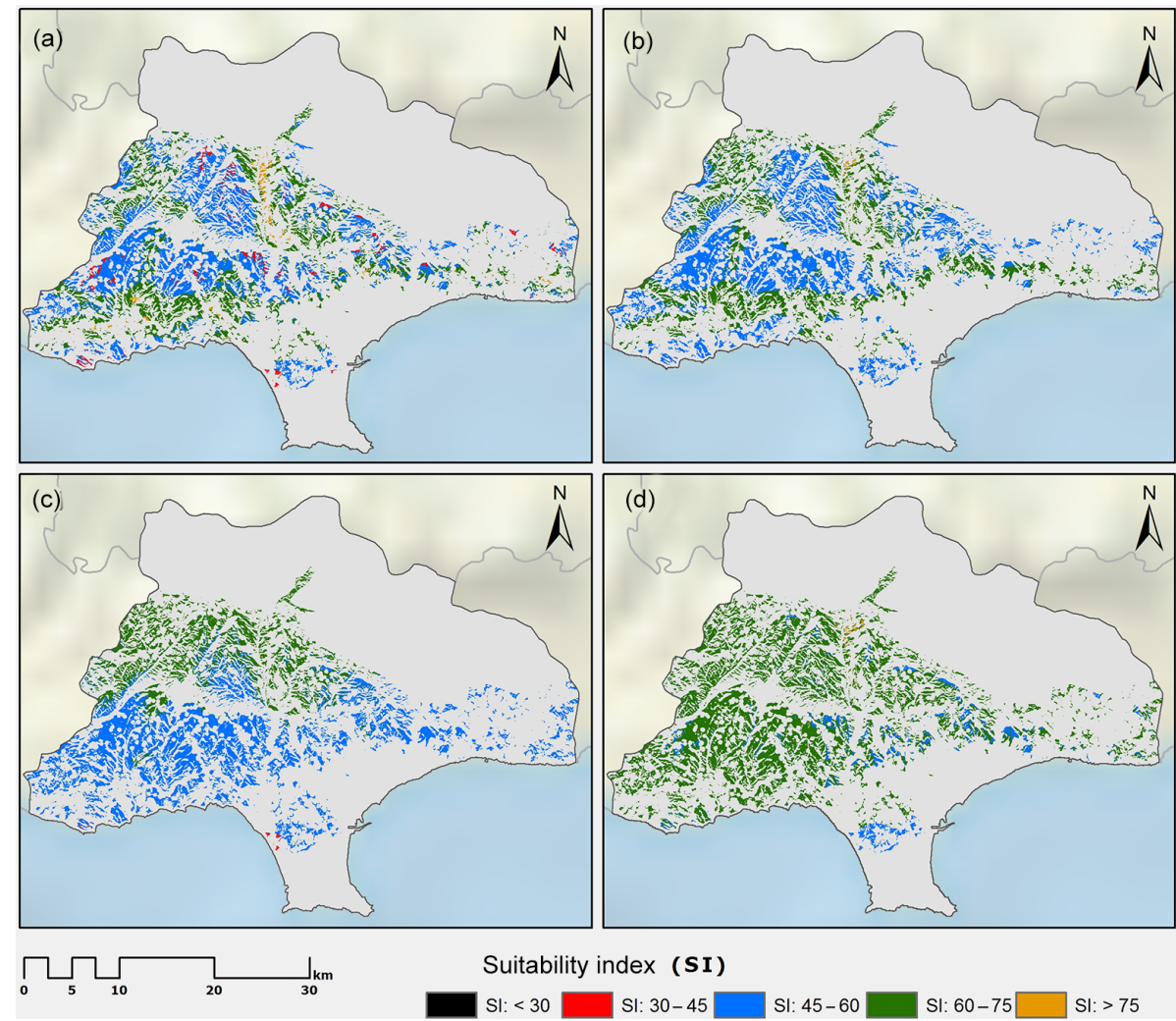

Figure 7. Classified results of sensitivity analysis and comparison among different scenarios: (a) case 1, (b) case 2, (c) case 3, and (d) case 4.

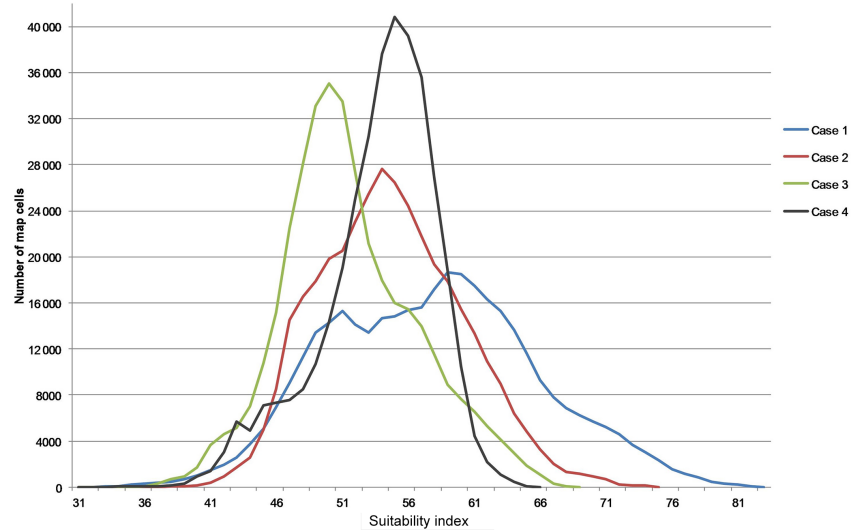

Figure 8. Number of map cells for each case of sensitivity analysis.

\section{Conclusions}

This study presents a model, which can be easily used to evaluate large areas for optimal site selection for a solar park. Such a model can be very helpful for potential investors to locate potential sites for solar energy exploitation, before carry out a detailed field survey.

Although there are several implementations of siting models within the GIS framework (Carrion et al., 2008; Tegou et al., 2010; Kontos et al., 2005; Georgiou et al., 2012; Maser et al., 2006; Ramachandra et al., 2007), the combination of MCA, AHP, and a GIS in an integrated platform is not common. In this article, a decision analysis methodological framework for solar energy exploitation and site evaluation is developed and applied in the Limassol district in Cyprus. The framework it is a combination of already existing tools such as multi-criteria analysis, AHP, and integrated site evaluation in a straightforward way. It also combines GIS and remote sensing techniques for spatial analysis, modeling, and visualization. The objective of the paper is to propose a method for solar park installation suitability analysis, taking into account a number of financial, social, environmental, and technical criteria. The pairwise comparison method in the context of the AHP was utilized to assign relative weights to the evaluation criteria, whereas the SAW was method used as a way for aggregating the used criteria, in order to compute the SI for each cell in the study area. A GIS established the spatial dimension of constrains and evaluation criteria and elaborated them for the production of the overall suitability map. A sensitivity analysis on the weights of the evaluation criteria was also performed, showing that each criterion is influential in the evaluation of the suitability of a site.

The results identified promising sites for electricity generation from solar energy, excluding over $80 \%$ of the whole 
study region. The best score areas $(\mathrm{SI}>75)$ cover only $3.0 \%$ $\left(40.3 \mathrm{~km}^{2}\right)$ of the study area. However, the proposed methodology allows the analyst to consider even less suitable sites, by reducing the acceptable threshold of suitability index. This would result in the identification of more areas as appropriate for solar park development in combination with field inspection. Thus, future work could include the individual assessment of the optimal locations in conjunction with field inspection in order to make the final selection of sites.

The innovative aspect of this work derives from the proposed tool as currently implemented within a local GIS, which provides a versatile platform of analysis and semiautomation of the operations, which might also extended into full automation and has a prospect for future web automation platform. This work derives a holistic approach from criteria selection and evaluation, data gathering and multicriteria analysis. That makes the tool flexible that encourages several "what if" scenarios to be easily implemented. In addition, an innovator dimension gives the balanced approach among practice, the way that evaluation criteria were used in conjunction with the legislative boundary constrains under a unified multi-criteria decision aiding. Finally, it provides accuracy and precision in less evaluation time, allowing for checking the robustness and stability of the results obtained. For these reasons, it may well be helpful for potential investors in solar park investments and also in other kinds of project sitting, due to the generic nature of the framework. In addition, the proposed GIS model may be further developed with contributions from EAC's experts, in order to become a valuable tool for sitting small, medium, or large solar parks, through adaptation of the basic model presented here.

Acknowledgements. The authors would like to thank the public services of Cyprus (Ministry of Agriculture Natural Resources \& Environment, Electricity Authority of Cyprus and Geological Survey Department) for offering their data, valuable help, and remarks for this research.

Edited by: L. Eppelbaum

Reviewed by: two anonymous referees

\section{References}

Bahadori, A. and Nwaoha, C.: A review on solar energy utilization in Australia, Renew. Sust. Energ. Rev., 18, 1-5, 2013.

Cameron, D. R., Cohen, B. S., and Morrison, S. A.: An approach to enhance the conservation-compatibility of solar energy development, PloS One, 7, e38437, doi:10.1371/journal.pone.0038437, 2012

Carrion, A. J., Estrella, E. A., Dols, A. F., Toro, Z. M., Rodriquez, M., and Ridao, R. A.: Environmental decision-support systems for evaluating the carrying capacity of land areas: Optimal site selection for grid-connected photovoltaic power plants, Renew. Sust. Energ. Rev., 12, 2358-2380, 2008.
European Commission: Science for Environment Policy. Future Brief: Wind \& Solar energy and nature conservation, Issue 9, December 2014.

Georgiou, A., Polatidis, H., and Haralambopoulos D.: Wind energy resource assessment and development: Decision analysis for site evaluation and application, Energy Sources, Part A: Recovery, Utilization, and Environmental Effects, 34, 1759-1767, 2012.

Hangiu, X.: Extraction of Urban Built-up Land Features from Landsat Imagery Using a Thematic-oriented Index Combination Technique, Photogramm. Eng. Rem. S., 73, 1381-1391, 2007.

Haoxu, L., Yaowen, X., Lin, Y., and Lijun, W.: A Study on the land cover classification of the arid region based on Multi-temporal TM images, ESIAT, 2011.

Hernandez, R. R., Easter, S. B., Murphy-Mariscal, M. L., Maestre, F. T., Tavassoli, M., Allen, E. B., Barrows, C. W., Belnap, J., Ochoa-Hueso, R., Ravi, S., and Allen, M. F.: Environmental impacts of utility-scale solar energy, Renew. Sust. Energ. Rev., 29, 766-779, 2014.

Katsaprakakis, D. A.: A review of the environmental and human impacts from wind parks. A case study for the Prefecture of Lasithi, Crete, Renew. Sust. Energ. Rev., 16, 2850-2863, 2012.

Katzner, T., Johnson, J. A., Evans, D. M., Garner, T. W. J., Gompper, M. E., Altwegg, R., Branch, T. A., Gordon, I. J., and Pettorelli, N.: Challenges and opportunities for animal conservation from renewable energy development, Anim. Conserv., 16, 367-369, 2013.

Kontos, Th., Komilis, D., and Halvadakis, K.: Sitting MSW landfills with a spatial multiple criteria analysis methodology, Waste Manage., 25, 818-832, 2005.

Law 29(I)/2005: Town and Country planning, Cypriot House of Representatives, 2005.

Mari, R., Bottai, L., Busillo, C., Calastrini, F., Gozzini, B., and Gualtieri, G.: A GIS-based interactive web decision support system for planning wind farms in Tuscany (Italy), Renew. Energ., 36, 754-763, 2011.

Masera, O., Ghilardi, A., Drigo, R., and Trossero, M. A.: WISDOM: A GIS-based supply demand mapping tool for woodfuel management, Biomass and Bio-energy, 30, 618-637, 2006.

Maxoulis, N. C. and Kalogirou, A. S.: Cyprus energy policy: The road to the 2006 world renewable energy congress trophy, Renewable Energ., 33, 355-365, 2008.

Pilavachi, P. A., Kalamalikas, N. G., Kakouris, M. K., Kakaras, E., and Giannakopoulos, D.: The energy policy of the Republic of Cyprus, Energy, 34, 547-554, 2009.

Ramachandra, T. V. and Shruthi, B. V.: Spatial mapping of renewable energy potential, Renew. Sust. Energ. Rev., 11, 1460-1480, 2007.

Saaty, T.: The Analytic Hierarchy Process, McGraw - Hill, New York, 1980.

Saaty, W. R.: The Analytic Hierarchy Process - What it is and how it is used, Math Modelling, 9, 161-176, 1987.

Sanchez-Lozano, M. J., Teruel-Solano, J., Soto-Elvira, L. P., and Garcia-Cascales, S. M.: Geographical Information Systems (GIS) and Multi-Criteria Decision Making (MCDM) methods for the evaluation of solar farms locations: Case study in southeastern Spain, Renew. Sust. Energ. Rev., 24, 544-556, 2013.

Solangi, K. H., Islam, M. R., Saidur, R., Rahim, N. A., and Fayaz, H.: A review on global solar energy policy, Renew. Sust. Energ. Rev., 15, 2149-2163, 2011. 
Tegou, L. I., Polatidis, H., and Haralambopoulos, D.: Environmental management framework for wind farm sitting: Methodology and case study, J. Environ. Manage., 91, 2134-2147, 2010.

Torres-Sibille, A. C., Cloquell-Ballester, V. A., Cloquell-Ballester, V. A., and Ramirez, M. A. A.: Aesthetic impact assessment of solar power plants: An objective and a subjective approach, Renew. Sust. Energ. Rev., 13, 986-999, 2009.

Tsoutsos, T., Frantzeskaki, N., and Gekas, V.: Environmental impacts from the solar energy technologies, Energ. Policy, 33, 289296, 2005.
Turney, M. and Ftenakis V.: Environmental impacts from the installation and operation of large-scale solar power plants, Renew. Sust. Energ. Rev., 15, 3261-3270, 2011.

Zanter, K.: LANDSAT 8 (L8) Data users handbook, USGS, 17-65, 2016.

Zha, Y., Gao, J., and Ni, S.: Use the normalized difference built-up index in automatically mapping urban areas from TM imagery, Int. J. Remote Sens., 24, 583-594, 2003. 